\title{
Evolutionary consequences of age-specific harvesting: age at first reproduction
}

\author{
Kornkanok Bunwong ${ }^{1,2+}$ and Wichuta Sae-jie $\mathrm{e}^{2,3^{*}+}$
}

\section{"Correspondence:}

wichuta.sa@psu.ac.th

${ }^{2}$ Centre of Excellence in

Mathematics, CHE, Si Ayutthaya

Road, Bangkok, 10400, Thailand

${ }^{3}$ Department of Applied

Mathematics and Informatics, Faculty of Science and Industrial Technology, Prince of Songkla University, Surat Thani Campus, Surat Thani, 84000, Thailand Full list of author information is available at the end of the article

${ }^{\dagger}$ Equal contributors

\section{Springer}

\begin{abstract}
The aim of this paper is to investigate harvest-induced evolution in life-history strategies of a harvested single-species population. In particular, we analyze evolution of the trait age at first reproduction. The population is grouped into four age classes, namely, zero-year-olds (newborns), one-year-olds (juveniles), two-year-olds (small adults), and individuals aged three years or older (large adults). The population is assumed to consist of a 'resident' group and a 'variant' group that are identical except that the resident group usually first reproduces as a large adult and the variant group usually first reproduces as a small adult. The effect of various age-dependent harvesting strategies on the dynamics is studied both analytically and numerically. It is shown that age-dependent harvesting strategies can cause evolution from the resident group to the variant group. In addition, we show that a limit on the harvesting of the resident group can yield a sustainable fishery of the commercially preferred resident group.
\end{abstract}

MSC: 39A30; 92B05

Keywords: age at first reproduction; age-selective harvesting; age-structured model; harvesting; invasion fitness; life-history evolution

\section{Introduction}

During recent decades, evidence of collapse of commercial fish populations has been accumulating [1-5]. One change in fish populations that surprised almost everyone is illustrated in Figure 1. As the figure shows, the age, weight, and length of first-time reproducing cod in the Northeast Arctic have declined dramatically from the 1930s to the 2000s [1]. Intensive studies reveal that the phenomenon could be a result of changing environmental conditions such as food availability and increases in ocean temperatures $[6,7]$ or overfishing $[8,9]$. Numerous studies have now convinced marine biologists that overfishing is a major threat to commercial fish populations $[4,10,11]$.

There is now accumulating evidence that harvesting can lead to evolutionary changes in life-history traits of fish that in turn affect their life cycle. Common developmental stages during the life cycle of a fish are: (1) egg, (2) larva, (3) juvenile, and (4) adult [12]. However, individual fish can differ in life-history traits [13] such as age at first reproduction, number and size of offspring, reproductive lifespan and ageing [14]. There is now evidence that supports the hypothesis that larger and older fish produce more and higher quality eggs

(c) The Author(s) 2017. This article is distributed under the terms of the Creative Commons Attribution 4.0 International License (http://creativecommons.org/licenses/by/4.0/), which permits unrestricted use, distribution, and reproduction in any medium, provided you give appropriate credit to the original author(s) and the source, provide a link to the Creative Commons license, and indicate if changes were made. 


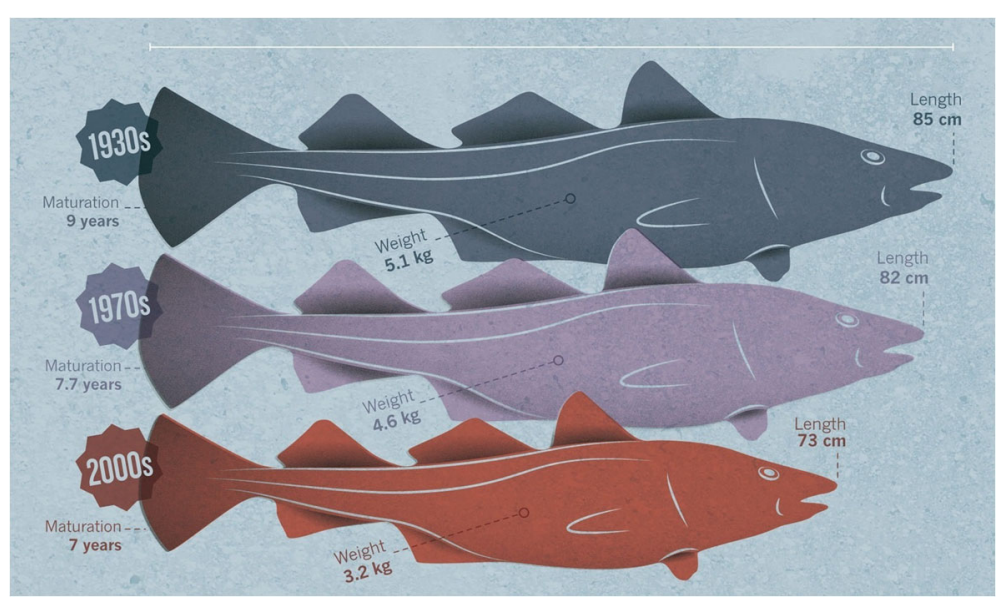

Figure 1 Northeast Arctic cod body sizes have declined [1].

than younger fish. As a result, in the absence of harvesting, these larger and older fish are naturally selected [10]. Examples of this are fish species such as pink salmon [11], South Atlantic red snapper [4], and barramundi [15]. Larger fish also tend to have longer life spans; for example, South Atlantic red snapper live up to 54 years [4] and barramundi up to 20 years [16].

Since the second World War, there have been rapid improvements in fish finding and harvesting techniques with the development of scientific location methods such as fish finders and the development of size-selective harvesting methods such as net mesh size [17]. There has also been economic pressure on fishermen to harvest the more valuable larger old fish and not harvest the smaller young fish. As a result of this targeting of bigger fish, commercial fish populations are changing to populations of smaller and weaker fish [18]. For example, Crocket [4] has reported that it is now rare to find South Atlantic red snapper older than 10 years. The declining size in fish populations also tends to be related to behavioral changes and/or genetic changes resulting in slower growth rates and a smaller size at maturity [11].

The evolutionary consequences of harvesting are now well established and strongly supported by empirical evidence [2,3,19-21]. As a result, there has been increased interest in developing mathematical models to analyze the effect of harvesting on the life-history traits of fish and their life cycles [22-26]. A variety of theoretical approaches dealing with life-history traits have been proposed in the literature. Cisneros-mata et al. [22] used an age-structured, discrete-time model to investigate population dynamics of the Pacific sardine. Age structure, density-dependent recruitment, environmental forcing, and fishing were included in the model. The sardine population in the model was divided into two age classes, namely, a juvenile (recruits) class and an adult class. Ernande et al. [24] constructed a life-cycle model with three classes, namely, larvae, juveniles, and adults. They assumed that the larvae transformed into juveniles through metamorphosis, that the juveniles transformed into adults through a maturation process, and that the adults then gave birth to the larvae. Ernande et al. investigated the effect of harvesting on age and size at maturation. Gårdmark et al. [23] and Miethe et al. [25] constructed discrete-time models for single fish populations. Gårdmark et al. divided the harvested population into three age classes, namely, one-year-olds, two-year-olds, and greater than or equal to three years 
old, and used the model to study the effects of age-selective harvesting on the evolution of age at first reproduction. On the other hand, Miethe et al. classified a fish population into four stages, namely, small juveniles, large juveniles, small adults, and large adults. They explored the evolutionary effect of fishing on size at maturation by assuming the existence of two populations of the same species differing only in the probability of age at first reproduction. Poos et al. [26] studied a continuous-time differential equation model of a size-structured population. In some models, the authors (see, e.g., [23]) consider that first reproduction can occur at different ages, whereas other authors (see, e.g., [25]) consider that maturation can occur at different size.

Motivated by the work of Gårdmark et al. [23], we develop discrete-time, age-structured population models for a single species differing only in the trait of age at first reproduction. We assume that a 'resident' population usually reproduces first at age three and that a 'variant' population usually reproduces first at age two. We investigate the evolutionary effects of age-selective harvesting on the ratios of the resident and variant populations both analytically and numerically. We also consider the effects of placing age limits on age-selective harvesting and show that these limits can be used as control measures to maintain a sustainable fishery of the resident population.

\section{A fixed life-history trait}

In this section, we construct a discrete-time age-structured life-history model. The time steps are assumed to be one year. We focus on the interaction between individuals in each age class with a fixed life-history trait. As stated previously, we assume that the individuals in the fish population are identical except that a resident group usually reproduces first at three years and a variant group usually reproduces first at two years.

\subsection{Age-structured population dynamics}

A suitable age-structured model for many fish species is to separate the population into yearly groups [12]. Since the time for egg hatching is relatively short, e.g., barramundi (1-2 days) [16], we merge two groups, i.e., egg and larva together under the name 'newborn'. Based on the fact that individual fish take various times to reach maturity and be able to produce offspring, e.g., cod in the Irish Sea (reach maturity at two to three years old) [21] and barramundi (reach maturity at three to four years old) [16], we assume that adult fish can be separated into a small adult group and a large adult group. Consequently, in the model we are considering, the population can be separated into four age groups of (1) newborns (age 0-1 year), (2) juveniles (age 1-2 years), (3) small adults (age 2-3 years), and (4) large adults (ages greater than or equal to 3 years) as illustrated in Figure 2. We assume that the life cycle of the fish population is as shown in Figure 3. The definitions and biological meanings of the variables and parameters in Figure 3 are given in Table 1.

Figure 2 Age-class diagram.

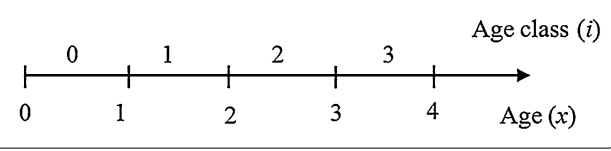




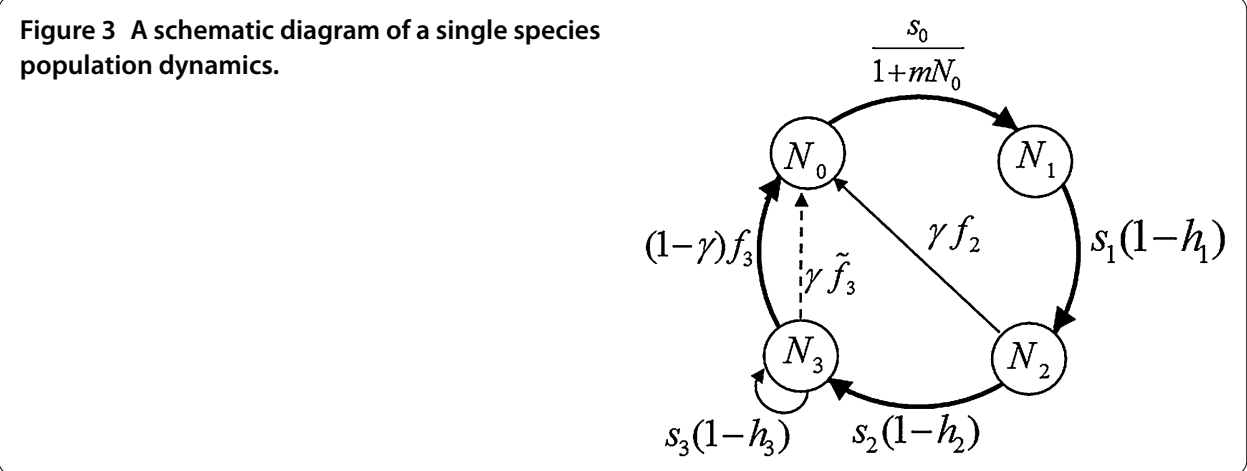

Table 1 Definition of model variables and parameters, adapted from [25]

\begin{tabular}{|c|c|c|}
\hline Notation & Description & $\begin{array}{l}\text { Range of } \\
\text { value }\end{array}$ \\
\hline \multicolumn{3}{|l|}{ Variables } \\
\hline$N_{0}$ & Density of newborn individuals & \\
\hline$N_{1}$ & Density of juvenile individuals & \\
\hline $\mathrm{N}_{2}$ & Density of small adult individuals & \\
\hline$N_{3}$ & Density of large adult individuals & \\
\hline \multicolumn{3}{|c|}{ Parameters } \\
\hline$\gamma$ & Probability of early reproduction & {$[0,1]$} \\
\hline$f_{2}$ & Per capita annual fecundity of early reproducing individuals at age 2 years old & \\
\hline$f_{3}$ & $\begin{array}{l}\text { Per capita annual fecundity of late reproducing individuals at age greater than or } \\
\text { equal to } 3 \text { years old }\end{array}$ & \\
\hline$\tilde{f}_{3}$ & $\begin{array}{l}\text { Per capita annual fecundity of early reproducing individuals at greater than or } \\
\text { equal to } 3 \text { years old }\end{array}$ & \\
\hline$h_{i}$ & Per capita annual harvest proportion of individuals at age $i(i=1,2,3)$ & {$[0,1]$} \\
\hline$c$ & Proportional reduction is measured by a cost & \\
\hline$m$ & $\begin{array}{l}\text { Constant that determines how strongly the survival of newborn is adversely } \\
\text { affected by density in this age class }\end{array}$ & \\
\hline$s_{i}$ & Per capita annual survival probabilities of individuals at age $i(i=0,1,2,3)$ & {$[0,1]$} \\
\hline
\end{tabular}

We consider the following discrete-time model.

$$
\begin{aligned}
& N_{0}(t+1)=\gamma\left[f_{2} N_{2}(t)+\tilde{f}_{3} N_{3}(t)\right]+(1-\gamma) f_{3} N_{3}(t), \\
& N_{1}(t+1)=\frac{s_{0} N_{0}(t)}{1+m N_{0}(t)}, \\
& N_{2}(t+1)=s_{1}\left(1-h_{1}\right) N_{1}(t), \\
& N_{3}(t+1)=s_{2}\left(1-h_{2}\right) N_{2}(t)+s_{3}\left(1-h_{3}\right) N_{3}(t) .
\end{aligned}
$$

In this model, newborn fish can be born either from a small adult mother or from a large adult mother. We assume that the probability that a fish first reproduces as a small adult is $\gamma$ with fecundity $f_{2}$, and then the probability that a fish first reproduces as a large adult is $1-\gamma$. Then, if a large adult mother first reproduces as a small adult, we assume that its fecundity is $\tilde{f}_{3}$, whereas if the large adult mother first reproduces as a large adult, the fecundity is $f_{3}$. In model (1), it is assumed that the fraction of newborn fish surviving to be juveniles is limited by food resources and predation. A well-known model for this limiting function is the Monod function $\frac{s_{0}}{1+m N_{0}}$ (see, e.g., $[25,27]$ ) which is based on the assumption that survival is limited by the density of the newborn population. Other possible choices 
for the survival function include the logistic function which limits carrying capacity, the Michaelis-Menten model which also limits density, or Holling type II function [27]. In this paper, we have selected the Monod function as a reasonable choice to illustrate the effect of different harvesting strategies.

\subsection{Equilibrium population densities}

From equation (1), there are two equilibrium population densities, i.e., a trivial equilibrium $\left(N_{0}^{*}, N_{1}^{*}, N_{2}^{*}, N_{3}^{*}\right)=(0,0,0,0)$ and a sustainable equilibrium $E^{*}=\left(N_{0}^{*}, N_{1}^{*}, N_{2}^{*}, N_{3}^{*}\right)$, where

$$
\begin{aligned}
& N_{0}^{*}=\frac{1}{m}\left[\frac{\left[\left(\tilde{f}_{3}-f_{3}\right) \gamma+f_{3}\right] s_{0} s_{1} s_{2}\left(1-h_{1}\right)\left(1-h_{2}\right)}{1-s_{3}\left(1-h_{3}\right)}+\gamma f_{2} s_{0} s_{1}\left(1-h_{1}\right)-1\right], \\
& N_{1}^{*}=\frac{s_{0} N_{0}^{*}}{1+m N_{0}^{*}}, \\
& N_{2}^{*}=\frac{s_{0} s_{1} N_{0}^{*}\left(1-h_{1}\right)}{1+m N_{0}^{*}}, \\
& N_{3}^{*}=\frac{s_{0} s_{1} s_{2}\left(1-h_{1}\right)\left(1-h_{2}\right) N_{0}^{*}}{\left(1+m N_{0}^{*}\right)\left[1-s_{3}\left(1-h_{3}\right)\right]} .
\end{aligned}
$$

The sustainable equilibrium exists with positive populations if and only if

$$
\gamma f_{2} s_{0} s_{1}\left(1-h_{1}\right)\left(1-s_{3}\left(1-h_{3}\right)\right)+\left[\left(\tilde{f}_{3}-f_{3}\right) \gamma+f_{3}\right] s_{0} s_{1} s_{2}\left(1-h_{1}\right)\left(1-h_{2}\right)>1 .
$$

\section{The effect of harvesting}

The effect of harvesting is to decrease the survival rates of the groups that are harvested. In the model in (1), the survival rate of group $i(i=1,2,3)$ is $s_{i}$ which is decreased to $s_{i}\left(1-h_{i}\right)$ if a fraction $h_{i}$ of age group $i$ is harvested. The main aim of this paper is to analyze the effects of different harvesting strategies on the survival rates of fish that first reproduce as small adults (choice of $h_{2}$ ) and the class that first reproduce as large adults (choice of $h_{3}$ ). Different harvesting strategies could be the use of large net size or targeting larger fish $\left(h_{3}>h_{2}\right)$ or targeting small adults $\left(h_{2}>h_{3}\right)$.

In order to study the effect of harvesting strategies on the age of first reproduction, we assume that the fish population can be separated into a resident class and a variant class which differ only in the probability of first reproducing as a small adult at two years old. For the resident class, we assume that the probability of first reproduction at two years old is $\gamma$, and for the variant class, we assume that the probability of first reproduction at two years old is $\gamma^{\prime}$. We will assume that, before harvesting, the resident class has a small probability $\gamma$ of reproducing as a small adult because the fecundity $f_{3}$ of a fish that first reproduces as a large adult is appreciably greater than the fecundities $f_{2}$ and $\tilde{f}_{3}$ of a fish that first reproduces as a small adult. We also assume that the variant class has a probability $\gamma^{\prime}>\gamma$ of reproducing as a small adult.

Assuming that the two classes differ only in the probability $\gamma$ and $\gamma^{\prime}$, we can obtain a model for the dynamics of the combined classes by considering the following 8-equation system, where the $N^{\prime}$ populations refer to the variant class with an increased probability 
$\gamma^{\prime}$ of first reproducing as a small adult.

$$
\begin{aligned}
& N_{0}(t+1)=\gamma\left[f_{2} N_{2}(t)+\tilde{f}_{3} N_{3}(t)\right]+(1-\gamma) f_{3} N_{3}(t), \\
& N_{1}(t+1)=\frac{s_{0} N_{0}(t)}{1+m\left[N_{0}(t)+N_{0}^{\prime}(t)\right]}, \\
& N_{2}(t+1)=s_{1}\left(1-h_{1}\right) N_{1}(t), \\
& N_{3}(t+1)=s_{2}\left(1-h_{2}\right) N_{2}(t)+s_{3}\left(1-h_{3}\right) N_{3}(t), \\
& N_{0}^{\prime}(t+1)=\gamma^{\prime}\left[f_{2} N_{2}^{\prime}(t)+\tilde{f}_{3} N_{3}^{\prime}(t)\right]+\left(1-\gamma^{\prime}\right) f_{3} N_{3}^{\prime}(t), \\
& N_{1}^{\prime}(t+1)=\frac{s_{0} N_{0}^{\prime}(t)}{1+m\left[N_{0}(t)+N_{0}^{\prime}(t)\right]}, \\
& N_{2}^{\prime}(t+1)=s_{1}\left(1-h_{1}\right) N_{1}^{\prime}(t), \\
& N_{3}^{\prime}(t+1)=s_{2}\left(1-h_{2}\right) N_{2}^{\prime}(t)+s_{3}\left(1-h_{3}\right) N_{3}^{\prime}(t) .
\end{aligned}
$$

\subsection{Invasion strategy}

We first consider the effect of introducing a small population of the early reproducers (the variant population) into an equilibrium population of the late reproducers (the resident population). The small variant population will decrease if all eigenvalues of the Jacobian matrix of the variant population at the equilibrium resident population (equation (1)) have absolute value less than one but will increase and start to invade the resident population if any eigenvalue has absolute value greater than one.

The Jacobian matrix of variant population (equation (3)) at the resident equilibrium point is

$$
\mathbf{J}=\left[\begin{array}{cccc}
0 & 0 & \gamma^{\prime} f_{2} & \left(\tilde{f}_{3}-f_{3}\right) \gamma^{\prime}+f_{3} \\
\frac{s_{0}}{1+m N_{0}^{*}} & 0 & 0 & 0 \\
0 & s_{1}\left(1-h_{1}\right) & 0 & 0 \\
0 & 0 & s_{2}\left(1-h_{2}\right) & s_{3}\left(1-h_{3}\right)
\end{array}\right]
$$

The corresponding characteristic polynomial is the determinant of $\mathbf{J}-\lambda \mathbf{I}$. Then we obtain the fourth-order equation in $\lambda$ as follows:

$$
\begin{aligned}
\lambda^{4}- & s_{3}\left(1-h_{3}\right) \lambda^{3}-\frac{s_{0} s_{1}\left(1-h_{1}\right) \gamma^{\prime} f_{2} \lambda}{1+m N_{0}^{*}}-\frac{s_{0} s_{1} s_{2}\left[\left(\tilde{f}_{3}-f_{3}\right) \gamma^{\prime}+f_{3}\right]\left(1-h_{1}\right)\left(1-h_{2}\right)}{1+m N_{0}^{*}} \\
& +\frac{s_{0} s_{1} s_{3} \gamma^{\prime} f_{2}\left(1-h_{1}\right)\left(1-h_{3}\right)}{1+m N_{0}^{*}}=0 .
\end{aligned}
$$

In order to calculate the invasion success of the variant population, we linearize the fourthorder polynomial in $\lambda$ by using Taylor series expansion around $\lambda=1$. The variant's invasion fitness [28] is then given by the following condition that the eigenvalue is increasing to greater than one.

$$
\lambda\left(\gamma^{\prime}, \gamma\right)=\frac{\left(\gamma^{\prime}-\gamma\right)\left[s_{0} s_{1}\left(1-h_{1}\right) A\right]}{B}+1
$$


where

$$
\begin{aligned}
& A=f_{2}\left(1-s_{3}\left(1-h_{3}\right)\right)+s_{2}\left(\tilde{f}_{3}-f_{3}\right)\left(1-h_{2}\right), \\
& B=\left(4-3 s_{3}\left(1-h_{3}\right)\right)\left(1+m N_{0}^{*}\right)-s_{0} s_{1} \gamma^{\prime} f_{2}\left(1-h_{1}\right) .
\end{aligned}
$$

\subsection{Evolutionary analysis}

As shown in [23], a variant population can start to invade the resident population if and only if the probability of early reproduction of the variant population is greater than the probability of early reproduction of the resident population, i.e., $\gamma^{\prime}>\gamma$ and the fecundity of two-year-olds satisfies the inequalities

$$
\begin{aligned}
f_{2} & >\frac{\left(f_{3}-\tilde{f}_{3}\right) s_{2}\left(1-h_{2}\right)}{1-s_{3}\left(1-h_{3}\right)}, \\
f_{2} & <\frac{\left(4-3 s_{3}\left(1-h_{3}\right)\right)\left(1+m N_{0}^{*}\right)}{\gamma^{\prime} s_{0} s_{1}\left(1-h_{1}\right)} .
\end{aligned}
$$

These inequalities can be restated as the following inequalities for the harvesting level $h_{3}$ of the large adult population.

$$
\begin{aligned}
& h_{3}>1-\frac{1}{s_{3}}\left[1+\frac{s_{2}\left(\tilde{f}_{3}-f_{3}\right)\left(1-h_{2}\right)}{f_{2}}\right], \\
& h_{3}>\frac{1}{3 s_{3}}\left[\frac{s_{0} s_{1} \gamma^{\prime} f_{2}\left(1-h_{1}\right)}{1+m N_{0}^{*}}-4\right]+1 .
\end{aligned}
$$

For sustainable fishery with the resident population of late reproducing fish, at least one of the above conditions should fail. In practice, the easiest condition to control is the value of $h_{3}$, i.e., place an upper limit on the proportion of large adult fish harvested.

Unfortunately, in many commercial fisheries, a target is usually to harvest the large adult fish population and to protect the juvenile and small adult populations, i.e., to set $h_{1}=$ $h_{2}=0$. In this case, the per capita annual survival probability at age two for both classes of fish satisfies the inequality

$$
s_{2}<\frac{f_{2}\left(1-s_{3}\left(1-h_{3}\right)\right)}{\left(f_{3}-\tilde{f}_{3}\right)} \text {. }
$$

On the contrary, if small adult individuals are harvested $\left(h_{2} \neq 0\right)$, then the per capita annual survival probability at age two is governed by the following inequality:

$$
s_{2}<\frac{f_{2}\left(1-s_{3}\left(1-h_{3}\right)\right)}{\left(f_{3}-\tilde{f}_{3}\right)\left(1-h_{2}\right)} .
$$

Then, the per capita annual survival probability at age three satisfies

$$
s_{3}<\frac{f_{2}-\left(f_{3}-\tilde{f}_{3}\right) s_{2}\left(1-h_{2}\right)}{f_{2}\left(1-h_{3}\right)} .
$$

We now consider the effect of the energy requirement imposed on the small adult fish by early reproduction. Because of energy allocation between growth and reproduction, we assume that early reproduction is associated with an energy cost $c$. We consider two cases: 
(1) individuals reproducing at age two have sufficient energy for reproduction and growth but their growth is slower than that of small adults who do not reproduce, (2) individuals first reproducing at age two do not have sufficient energy for reproduction and growth.

Case I: We assume that the fecundity of the fish at age two is not reduced, but the reduced growth reduces the fecundity of the fish at age three, i.e., $\tilde{f}_{3}=f_{3}(1-c)$ where $0 \leq$ $c \leq 1$.

Case II: $\tilde{f}_{3}=f_{2}(1-c)$ where $0 \leq c \leq 1$.

If age at first reproduction of individuals is two, at age three their fecundities are reduced proportionally to their own fecundity at age two.

\section{Numerical results}

For all numerical solutions of (2)-(3), the initial condition is $\left(N_{0}(0), N_{1}(0), N_{2}(0)\right.$, $\left.N_{3}(0), N_{0}^{\prime}(0), N_{1}^{\prime}(0), N_{2}^{\prime}(0), N_{3}^{\prime}(0)\right)=(446.4,30.86,27.78,14.88,446.4,30.86,27.78,14.88)$ and starting time is $t_{0}=1$.

As illustrated in Figure 4 , the $\left(h_{2}, h_{3}\right)$ parameter space can be separated into four regions depending on the qualitative behavior of the population dynamics. For all four regions, the values of the following parameters are fixed: $c=0.6, f_{2}=10, f_{3}=30, s_{2}=0.9$, and $s_{3}=0.8$. For all regions, we have also considered two cases of $\tilde{f}_{3}$; i.e., $f_{2}(1-c)$ and $f_{3}(1-c)$.

In Region $\mathrm{I}, A>0$ and $B<0$ for both cases $\tilde{f}_{3}=f_{2}(1-c)$ and $\tilde{f}_{3}=f_{3}(1-c)$. As shown in Figure 5, both the resident and variant populations are overfished and die out.

In Region II, $A>0, B>0$ for both $\tilde{f}_{3}=f_{2}(1-c)$ and $\tilde{f}_{3}=f_{3}(1-c)$. As shown in Figure 6, the variant group of individuals first reproducing at age two invades the resident group and becomes the dominant group.
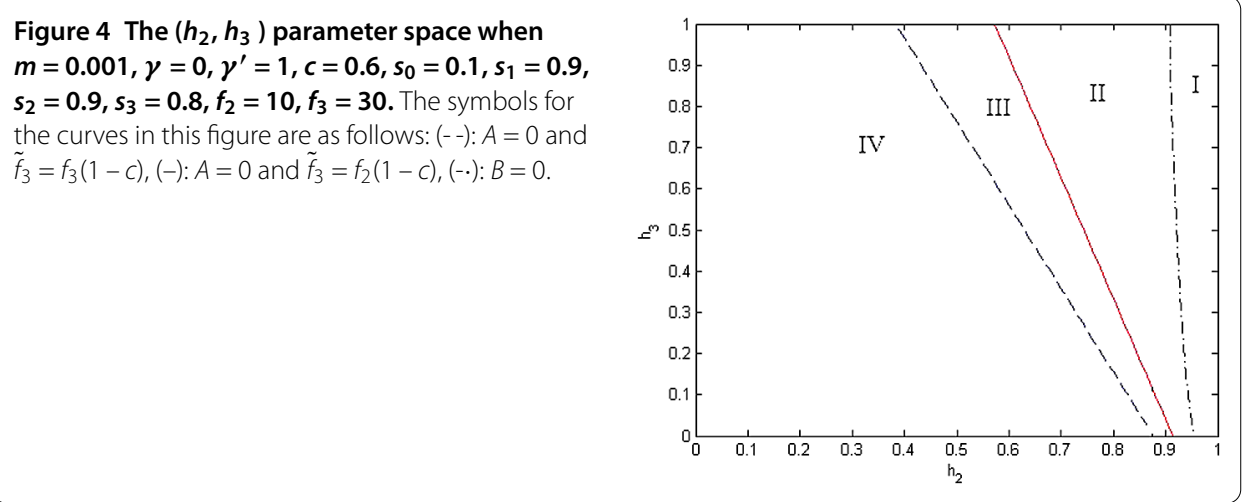

Figure 5 Region I. Parameters: $h_{2}=0.99, h_{3}=0.8$.

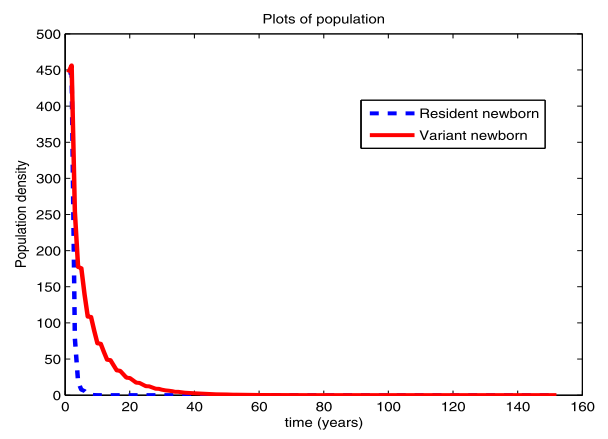


Figure 6 Region II. Parameters: $h_{2}=0.8, h_{3}=0.5$.
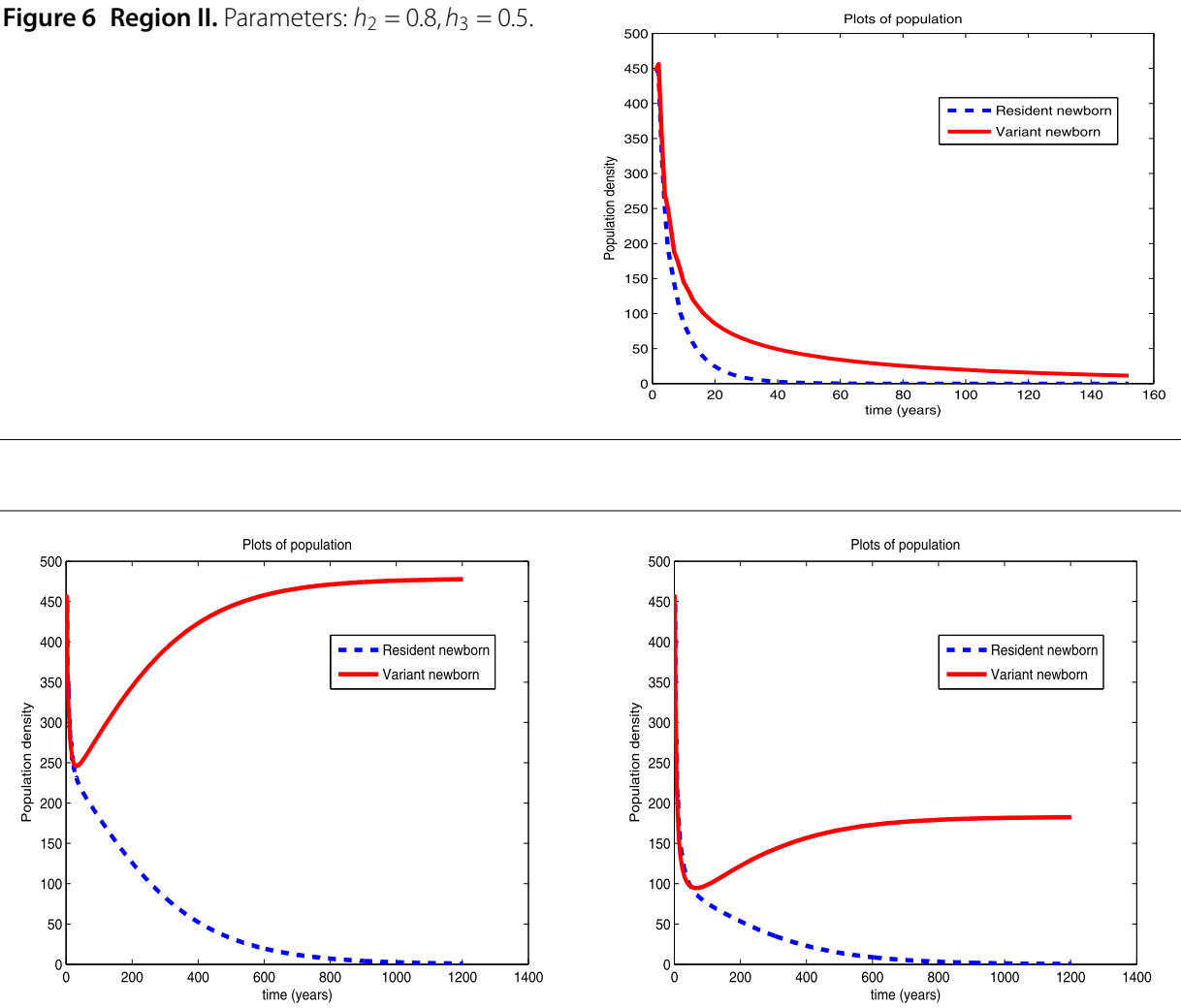

Figure 7 Region Illa. Plot of newborn populations vs time. Parameters: $h_{2}=0.5, h_{3}=0.8$ on the left $h_{1}=0$ and on the right $h_{1}=0.2$.

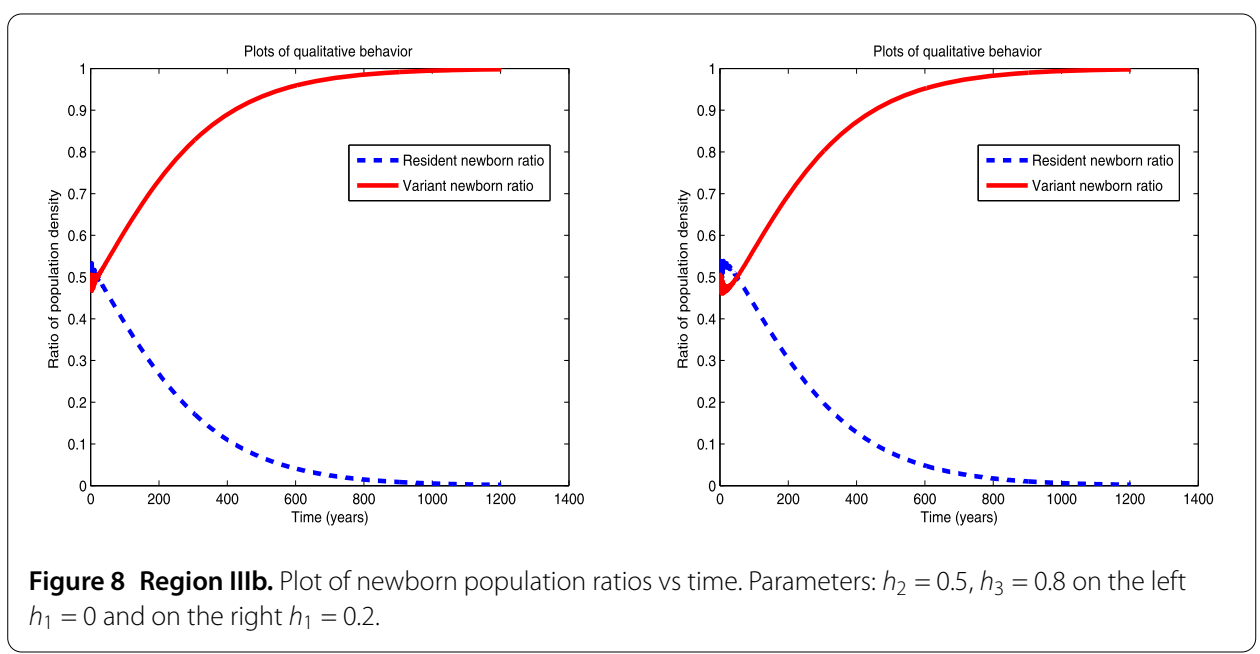

In Region III, there are two conditions of (1) $A>0$ and $B>0$ for $\tilde{f}_{3}=f_{3}(1-c)$ and (2) $A<0$ and $B>0$ for $\tilde{f}_{3}=f_{2}(1-c)$. The individuals first reproducing at age two can then invade if their fecundity at age three is lower than the fecundity of the same-age individuals first reproducing at age three $\left(\tilde{f}_{3}=f_{3}(1-c)\right.$ ) (see Figures 7 and 8 ).

In Region IV, $A<0, B>0$, the resident population remains the dominant population and the variant population cannot invade (see Figures 9 and 10). 

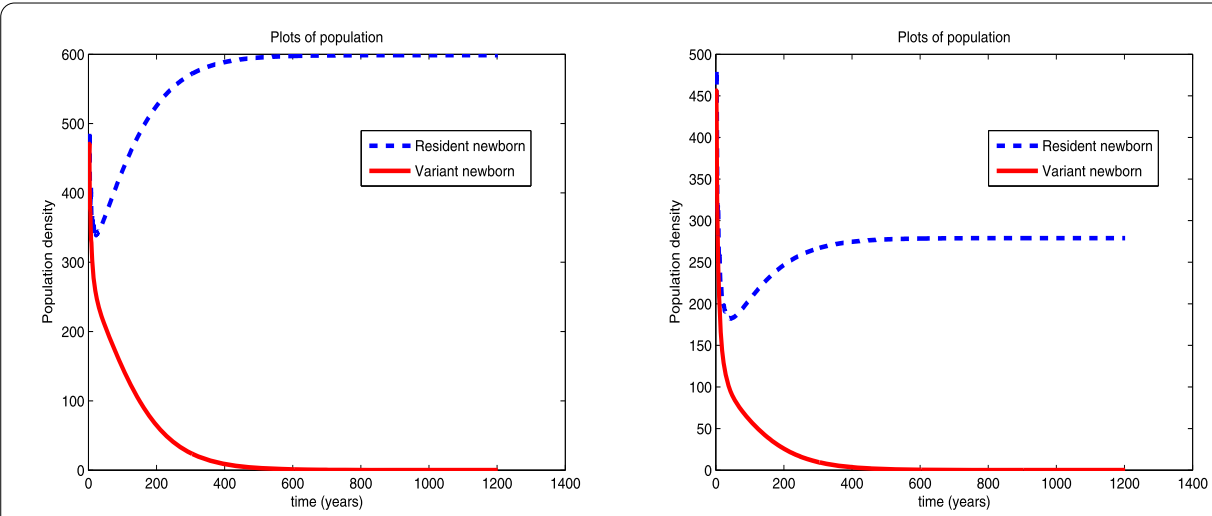

Figure 9 Region IVa. Plot of newborn populations vs time. Parameters: $h_{2}=0.5, h_{3}=0.7$ on the left $h_{1}=0$ and on the right $h_{1}=0.2$.

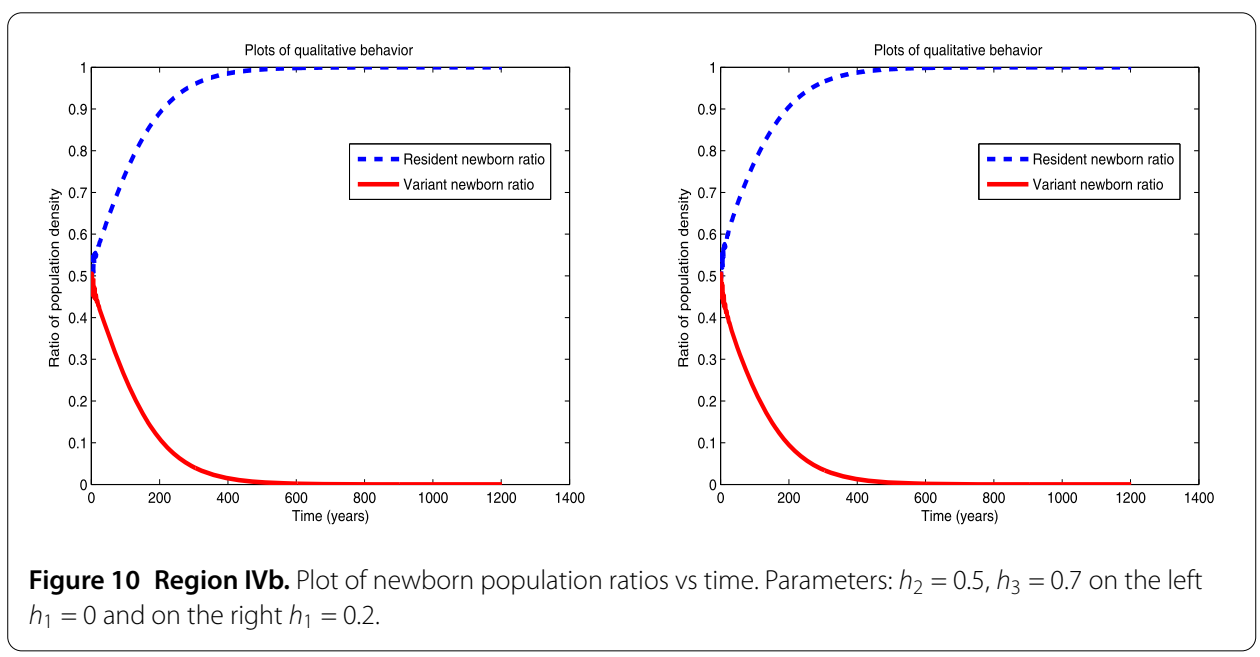

It is clear from these results that changing the age-selective harvesting strategy, i.e., changing the values of $h_{2}$ and $h_{3}$, can change the dominant population from the commercially preferred late reproducing resident group to the less preferred early reproducing variant group.

\section{Discussion}

In this paper, we have studied the effect of age-dependent harvesting strategies on the life-history trait of age at first reproduction in a single species. We have assumed that the species can be separated into a resident group that usually reproduces at age greater than or equal to three years and a variant group that usually reproduces at age two years. In all organisms, the growing phase and the reproduction phase of an individual require energy. Before maturity, energy is mainly allocated for growth, but once an individual begins to reproduce, a part of the energy is required for reproduction activities [13, 29]. According to this energy allocation balance, the size of an early reproducer should be smaller than the size of a late reproducer. One of the findings from our study is that one result of excessive harvesting of large adults is that only the individuals that start reproducing at age two can survive in the system. Consequently, the size of fish in the population can decrease. These results are consistent with the observational data discussed in the introduction that the 
size and age of fish in harvested populations have decreased. Our results have shown that a sustainable fishery of the commercially preferred larger, later reproducing fish can be obtained by limiting the value of $h_{3}$, i.e., by placing an upper limit on the proportion of large adult fish harvested.

In this paper, we have assumed that reproduction and maturation are closely related and occurs at the same age and size (length or weight). This assumption is often a good first approximation [30]. For example, the von Bertalanffy growth curve [31] can be used to estimate the size (length or weight) of a fish as a function of its age. However, in the realworld situation an age-class cohort may have a range of different sizes. Finally, different life-history traits such as fecundity and survival should also be considered and compared with early reproduction in terms of trade-offs $[32,33]$.

\section{Acknowledgements}

This research was financially supported by (1) the Department of Mathematics, Faculty of Science, Mahidol University, (2) the Centre of Excellence in Mathematics, Commission on Higher Education, Ministry of Education and (3) the Department of Applied Mathematics and Informatics, Faculty of Science and Industrial Technology, Prince of Songkla University, Surat Thani Campus. We would like to thank Dr. Elvin J. Moore and Dr. Anakewit Boonkasame for proofreading the manuscript.

\section{Competing interests}

The authors declare that they have no competing interests.

Authors' contributions

All authors contributed equally to writing of this paper. All authors read and approved the final manuscript.

\section{Author details}

${ }^{1}$ Department of Mathematics, Faculty of Science, Mahidol University, Rama VI Road, Ratchathewi District, Bangkok, 10400 Thailand. ${ }^{2}$ Centre of Excellence in Mathematics, CHE, Si Ayutthaya Road, Bangkok, 10400, Thailand. ${ }^{3}$ Department of Applied Mathematics and Informatics, Faculty of Science and Industrial Technology, Prince of Songkla University, Surat Thani Campus, Surat Thani, 84000, Thailand.

\section{Publisher's Note}

Springer Nature remains neutral with regard to jurisdictional claims in published maps and institutional affiliations.

Received: 8 February 2017 Accepted: 19 May 2017 Published online: 02 June 2017

\section{References}

1. Borrell, B: A big fight over little fish. Nature 493, 597-598 (2013)

2. Barot, $S$, Heino, $M, O$ 'Brien, L, Dieckmann, U: Reaction norms for age and size at maturation: study of the long-term trend (1970-1998) for Georges Bank and Gulf of Maine cod stocks. In: ICES CM Documents, pp. 1-25 (2002)

3. Barot, $S$, Heino, M, O'Brien, L, Dieckmann, U: Estimating reaction norms for age and size at maturation when age at first reproduction is unknown. Evol. Ecol. Res. 6, 659-678 (2004)

4. Crockett, L: Overfishing 101: the Importance of rebuilding our fish populations without delay. http://voices.nationalgeographic.com/2011/05/09/overfishing-101-the-importance-of-rebuilding-our-fishpopulations-without-delay/

5. Köster, F, Trippel, E, Tomkiewicz, J: Linking size and age at sexual maturation to body growth, productivity and recruitment of Atlantic cod stocks spanning the North Atlantic. Fish. Res. 138, 52-61 (2013)

6. Doogan, S: Why are some Alaska salmon and halibut getting smaller? https://www.adn.com/fishing/article/are-alaskan-fish-getting-smaller/2015/09/18/

7. Kuparinen, A, Merila, J: Detecting and managing fisheries-induced evolution. Trends Ecol. Evol. 22, 652-659 (2007)

8. Myers, RA, Cadigan, NG: Was an increase in natural mortality responsible for the collapse of northern cod? Can. J. Fish. Aquat. Sci. 52, 1274-1285 (1995)

9. Myers, RA, Barrowman, NJ, Hoenig, JM, Qu, Z: The collapse of cod in eastern Canada: the evidence from tagging data. ICES J. Mar. Sci. 53, 629-640 (1996)

10. Fishing; More protection for big ones. https://www.sciencedaily.com/releases/2014/01/140102112241.htm

11. Evolution: Library: Shrinking salmon. http://www.pbs.org/wgbh/evolution/library/10/3/I_103_02.html

12. Gloucester Maritime Heritage Center: FinFish Hatchery. http://seagrant.mit.edu/hatchery/lifecycle.html

13. Saborido-Rey, F, Kjesbu, O: Growth and maturation dynamics, 26 pp. (2005)

14. Berkeley: Life history traits. http://ib.berkeley.edu/labs/slatkin/eriq/classes/biol472/lectnotes/lect7_12LifeHistory.pdf

15. Some basic facts on barramundi. http://www.srilankaecotourism.com/barramundi_facts.htm

16. Barramundi. http://www.lenrex.com.au/fish-species/barramundi.9/

17. $\mathrm{Xu}, \mathrm{D}$ : The top 5 biggest bass world records. http://www.outdoorhub.com/stories/2014/10/31/top-5-biggest-bass-world-records/ 
18. Richard, M: By targeting bigger fish, we are breeding populations of smaller and weaker fish. https://www.treehugger.com/ocean-conservation/targeting-bigger-fish-we-are-breeding-populations-smallerfish.html

19. Conover, D: Smaller fish, smaller harvest. http://evolution.berkeley.edu/evolibrary/article/0_0_0/conover_05

20. Conover, D, Munch, S: Sustaining fisheries yields over evolutionary time scales. Science 297, 94-96 (2002)

21. Nash, RDM, Pilling, GM, Kell, LT, Shön, P-J, Kjesbu, OS: Investment in maturity-at-age and -length in northeast Atlantic cod stocks. Fish. Res. 104, 89-99 (2010)

22. Cisneros-Mata, M, Montemayor-López, GM, Nevárez-Martínez, M: Modeling deterministic effects of age structure, density dependence, environmental forcing, and fishing on the population dynamics of Sardinops sagax caerulea in the Gulf of California. CalCOFI Rep. 37, 201-208 (1996)

23. Gårdmark, A, Dieckmann, U, Lundberg, P: Life-history evolution in harvested populations: the role of natural predation. Evol. Ecol. Res. 5, 239-257 (2003)

24. Ernande, B, Dieckmann, U, Heino, M: Adaptive changes in harvested populations: plasticity and evolution of age and size at maturation. Proc. R. Soc. Lond. B 271, 415-423 (2004)

25. Miethe, T, Dytham, C, Dieckmann, U, Pitchford, J: Marine reserves and the evolutionary effects of fishing on size at maturation. ICES J. Mar. Sci. 67, 412-425 (2010)

26. Poos, J, Bränntröm, Å, Dieckmann, U: Harvest-induced maturation evolution under different life-history trade-offs and harvesting regimes. J. Theor. Biol. 279, 102-112 (2011)

27. Keshet, LE: Mathematical Models in Biology. Random House, New York (1987)

28. Metz, J, Nisbet, R, Geritz, S: How should we define 'fitness' for general ecological scenarios? Trends Ecol. Evol. 7, 198-202 (1992)

29. Winkle, VW, Shuter, B, Holcomb, B, Jager, H, Tyler, J, Whitaker, S: Regulation of energy acquisition and allocation to respiration, growth and reproduction: simulation model and example using rainbow trout. In: Early life history and recruitment in fish populations. Springer, Berlin (1997)

30. Allsop, Q, de Lestang, P, Griffin, R, White, G: Barramundi - your questions answered, Fisheries Research, Darwin. Fish Note, 1-5 (2006). http://www.territorystories.nt.gov.au/bitstream/10070/250118/1/FN27.pdf

31. Fisheries and Aquaculture Department: Von Bertalanffy growth equation. http://www.fao.org/docrep/W5449e/w5449e05.htm

32. Best, A, Bowers, R, White, A: Evolution, the loss of diversity and the role of trade-offs. Math. Biosci. 264, 86-93 (2015)

33. Bowers, R, Hoyle, A, White, A, Boots, M: The geometric theory of adaptive evolution: trade-off and invasion plots. J. Theor. Biol. 233, 363-377 (2005)

\section{Submit your manuscript to a SpringerOpen ${ }^{\circ}$ journal and benefit from:}

- Convenient online submission

Rigorous peer review

- Immediate publication on acceptance

- Open access: articles freely available online

- High visibility within the field

- Retaining the copyright to your article 